\title{
The relationship between anxiety, somatic symptoms and hardiness in adolescence
}

\author{
Ildikó Katalin Kovács ${ }^{1} \&$ Mária Borcsa ${ }^{2 *}$ \\ ${ }^{I}$ Faculty of Psychology and Educational Sciences, Babeş-Bolyai University, Cluj-Napoca, Romania \\ ${ }^{2}$ Psychology Doctoral Program, School of Human Sciences, University of Debrecen, Hungary
}

Received 28.09.2017; Received revised 17.12.2017; Accepted 30.12.2017 Available online 31.12.2017

\begin{abstract}
Anxiety is the most common psychological disorder in adolescence. If it is not recognized and treated properly it can cause somatic symptoms or sever illnesses. The aim of the present research is to study the relationship between anxiety and somatic symptoms. Furthermore, it is also an attempt to discover the role of hardiness in buffering stress and anxiety. We tried to find out if there is any difference in hardiness between adolescents with high level of anxiety and adolescents with low level of anxiety. The present study is a quantitative, non-experimental, descriptive study. The sample consists of 232 subjects, randomly chosen, 92 boys and 140 girls, average age is 13.55 years. We found that adolescents with high level of anxiety experience more somatic symptoms and they are less hardy than their peers with low level of anxiety. Overall anxiety explains the $46.1 \%$ of somatic symptoms. $26.3 \%$ of the somatic symptoms can be explained by trait anxiety and $19.8 \%$ of somatic symptoms can be explained by state anxiety. Non-hardy attitudes are only responsible for $17 \%$ of trait anxiety; it plays a non- determinant role in state anxiety and somatic symptoms. Anxiety and its relation to somatic symptoms are very complex phenomena. Forming out a hardy personality helps dealing with stressful, anxious periods, but hardiness by itself will not protect one from somatic symptoms and anxiety.
\end{abstract}

Keywords: anxiety, hardiness, somatic symptoms, stressful life events, adolescents.

Address of correspondence: Mária Borcsa, Psychology Doctoral Program, School of Human Sciences, University of Debrecen, H-4032 Debrecen, University Square 1, Hungary.

E-mail: borcsamaria67@gmail.com

\section{Introduction}

We are all facing a fast changing world. Differen people have very different reactions to novelties and new situations, some can cope with and adapt to it, some feel unsure and cannot keep up the pace. Changes challenge us by creating physical and psychological responses varying on a large spectrum: from excitement to distress or anxiety. Stress and anxiety often manifest in somatic symptoms. Are young adolescents vulnerable or are they resilient to stress? Some adolescents have favorable condition to form their techniques and instruments to get over with difficulties, some fails.

\section{Anxiety/ stress and somatic complaints}

Anxiety disorders are the most common psychological problems in childhood. They often cause weak cognitive and social development, and result poor educational outcomes (Beesdo-Baum, Knappe, 2012). Spielberger (1972) regards anxiety as principal causative agent for psychosomatic symptoms and it debilitates psychological functions. Based on Cattel and Scheier's (1961) factor analytic study, Spielberger (1972) defines trait anxiety as relative permanent personality characteristic. It is a predisposition to perceive harmless situations as threatening ones. People with high levels of trait anxiety respond to adversity with high state anxiety. They have intensive reactions, which are lopsided with the real situation. State anxiety is a momentary, conscious feeling of physical and psychological tensions.

Anxiety is an emotional state, which causes the automatic activation of the nervous system resulting the constant feeling of being threatened and tensioned. It can vary in intensity and fluctuate in time (Cruz et al, 2014). Anxiety, depression and major depressive disorder are frequently associated with somatic or chronic pain 
complaints, somatoform disorders like: dizziness, headache, musculoskeletal pain, nausea and gastrointestinal complaints. The collective noun for the symptoms above is functional pain symptoms; we have not sufficient medical explanation for their origin (Beesdo at al., 2010, Bekhuis at al. 2015, Fielding, Young, Martin, Walters, 2016). In 1990 Merikangas, Angst and Isler found significant correlation between migraine and anxiety (chronic migraine, lasting at least one year). They also found that patients who suffered from anxiety had a higher risk of developing phobias (16,4\% more) and panic disorders $(8,8 \%$ more $)$. Fielding, Young, Martin and Walters (2016) were comparing anxious and non-anxious children.

Taking into consideration the type and the duration of anxiety the following categories were set up: generalized anxiety disorder, social phobia, specific phobia, separation anxiety disorder, and panic disorder. Fielding at al. (2016) drew the conclusion that children with anxiety disorders, mainly anxious girls with separation anxiety disorder, have significantly higher headache symptoms; they suffer more frequent from primary headache. For better understanding, the connection between functional somatic syndromes, anxiety disorder, and anxious arousal Gold (2011) clarifies the conceptual framework. According to him, functional somatic syndrome contains the following symptoms: continuous fatigue, pain, problem with concentration and memory, gastrointestinal problems, insomnia. Anxiety disorder means: excessive and irrational fears, accompanied by dread as well as physical signs (pain, restless, fatigue) and anxiety arousal.

Individuals with high anxiety arousal often report difficulty with swallowing, feel muscle tension, nausea, trembling, they are irritable, sweating more, have the stimuli to urinate frequently, feeling out of breath and have hot flashes. Stress inspires us to be active, to fight against the unpleasant situation. However, if we are running out of energy, anxiety is escalating. Childhood anxiety, prolonged stress can cause serious consequences in adulthood (Dávid, 2014). Hans Selye (1979) in his book, 'The Stress of Life', emphasizes the physiology of chronic stress and the warning signs.

One important sign of chronic stress is pain felt either in the neck or lower pain and migraines. The intestinal system is also affected by stress, with patients complaining of diarrhea, indigestion, queasiness and even sometimes vomiting. Frequent urination is also present. Another indicator of chronic stress is sleepiness, fatigue- the continuous feeling of being tired and loss of the joy of life. Prolonged stress causes cognitive dysfunction like concentration problems, flight of thoughts, general disorientation. Chronic stress frequently manifests through emotional instability, general irritability, hyper excitation or depression and impulsive behavior. Concomitant with stress several signs and symptoms of anxiety/anxious arousal (fast heart beating, dryness of the throat and mouth, floating anxiety, emotional tension, nervous ticks, nervous laughter, sweating and nightmares) can be observed. Additionally to the indicators above Selye (1979) listed some other serious signs like: sleep disorder- insomnia or bruxism. As a serious consequence of stress we can encounter alcohol abuse drug (legally, illegally) abuse and addiction. During chronic stress people experience a distorted reality, they tell about unreal feelings, weakness, dizziness, and speech difficulties (stuttering). Many times people with chronic stress report loss or excessive appetite.
Neurotic behavior, psychoses, and accident proneness can be associated with stress (Selye, 1979).

Sadaghiani's (2011) study highlights the role of stress in several physical illnesses development: high blood pressure, stomach ulcer, asthma, arthritis, hyperactive thyroid, migraine, coronary heart disease, headache, diabetes. Besides the physical illnesses he enhances that long term stress can cause anxiety, depression, state of being moody, concentration and memory disorder, behavioral problems (nail biting), anorexia nervosa, insomnia, and hoarding (Hamblin, Lewin, Salloum, Crawford, McBride, Storch,2015).

\section{The role of hardiness in reducing stress, anxiety}

Since the ' 70 s, numerous scientists tried to understand what makes an individual to function properly during adversity. In literature we can find more expressions for the ability to withstand stress and anxiety, to respond properly to changes. Hardiness, resilience and adversity quotient (Stolz, 1997) are expressing merely the same concept. Some of the researchers say: it is an ability to resist and surmount adversity. Others consider that hardiness is a special personality trait, it enables us to resist stress or handle difficulties. Some consider hardiness as a key to be resilient to stress, a toolbar of strategies and attitudes. In the current study we use the approach of Maddi (2007) to understand the effect of hardiness on stress and anxiety.

Hardiness enables us to perform, stay focused during difficult times. Hardiness is a personality trait, helps people to adapt to new circumstances, to withstand adversities (Kobasa, 1979). Maddi (2007) considers hardiness as a pathway which leads a person to resiliency and gives courage in uncertainty. He says that specific attitudes and strategies can ameliorate stress. Individuals with high level of hardiness consider difficulties as possibilities for improving themselves. Hardiness is built up from three elements: control, commitment and challenge, determining human behaviors. Control helps people to stay active during threatening conditions. Those who have high level of control, remain active during unpleasant events, they believe that they can have influence on adverse conditions; they never feel lost in a problematic situation. Commitment is the answer why we do not run away during difficulties. If commitment is high, people stay involved, optimistic; they do not show the signs of detachment or alienation. People with high commitment concentrate on problem solving. Commitment assures the person to remain persistent in arduousness. Challenge provides people to think that changes and stress are part of life. People with high level of challenges consider hardiness as a possibility to learn, changes are seen as opportunities, a possibility for growth and development.

Patrick and Bernat (2009) define resiliency that not only the absence of anxiety symptoms, but also psychological hardiness and adjustment are present. They enucleated hardiness being a construct associated with resiliency. Hardiness is a personal characteristic, protects a person from negative (physical and mental) consequences of stress, increases health and decreases vulnerability (Bartone, Ursano, Wright, Ingraham, 1989, Connor, Davidson, 2003).

When people experience adverse situations the whole body responds; the nervous-, and endocrine systems produce physiological reactions. In situation of threat, several physiological responses can be detected like: 1.Cardiac muscle- results increased frequency 
(tachycardia) and increased strength of contraction; 2. Respiratory system-effects- faster breathing (tachypnea) and taking deeper breaths, help oxygenation of the blood; 3.Circulatory system-constriction of peripheral arteries favor larger blood flow to the main organs; 4. Liver liberates glucose into the blood; 5. Muscle and skeletal system enable voluntary muscle construction; 6 . The cortisol production increases, discharges glucocorticoids and adrenergic; 7. Vision contraction of the pupils assures better periphery vision, makes us able to observe possible escape ways, 8. Changes in excretory system affect the frequency of urination and also cause the loss of control over muscles involved in it (Ortega, Saavedra, 2014, Silverton, 2008, Koeppen and Stanton, 2009). During adversity, hardy people concentrate on problem solving, the spirit of survival comes up, and they remain positive and optimistic even if they may feel anguished or frustrated. Even if they are traumatized these people have the sense of self-efficiency, they remain self-confident and they are not losing their self-esteem.

Hardy people can turn obstacles into personal growth. Optimism enable them to percept their situation in a clear way by considering different perspectives; they can make proper decisions. Being persistent helps them to face adversity, overtake critical periods in their lives (Ortega, Saavedra, 2014).

Hardiness has a stress buffering effect, plays a crucial role in development and the course of disease (Maddi, 2013, Kobasa, 1979, Maddi, 2002). Sadaghiani (2011) came to the conclusion, that hardiness (learned cognitive, behavioral, interpersonal skills) can decrease stress and cause balance. Out of the three components of hardiness control is responsible for ameliorating perceived stress and stress syndromes. Beasley, Thompson and Davidson (2003) were investigating the relationship between life event stress, traumatic life experience, hardiness, coping styles, general health, somatization, anxiety and depression. They found out that hardy people have adaptive coping styles, they have less somatic symptoms, their general health is better, and hardiness supports mental and physical health against stress. Hardiness also has an effect on physical changes: it is associated with general health and psychological well-being. People with higher resilience and hardiness experience less psychological distress, symptoms of anxiety and depression (Haddadi, Besharat, 2010). Similar to Haddadi and Besharat (2010) findings Abdolhosseini, Hasel, Zalano (2012) found out that in stressful conditions people with high level of hardiness have lower systolic blood pressure and less hardy people have higher level of systolic blood pressure. Furthermore, hardiness, positive perfectionism and psychological well-being significantly correlate. Hardiness helps to decrease physiologic responses- blood pressure, heart rate, respiratory rate- (Besharat, Hasel, 2011). Hardy individuals percept less stress, they present lower level of somatic symptoms and anxiety, than non- hardy peers (Hanton, Evans, Neil, 2003, Wiebe, 1991). Sandvik at al. (2015) found that instability, antisocial behavior and low level of commitment increase the risk of experiencing anxiety. Medium strong negative correlation was found between hardiness- mainly the commitment componentand anxiety. Hardiness can be formed, during personal development one can learn to bounce back after a setback. Wolin and Wolin (1993) encountered seven behaviors resulting hardy personality: being able for insight, being independent, forming and keeping relationships, being initiative, having humor, creativity, and morality.

\section{The present study}

On the one hand, the aim of the present research is to better understand the relationship between anxiety and somatic symptoms. On the other hand, we would like to discover if there is any difference in hardiness between adolescents with high level of anxiety and adolescents with low level of anxiety. According to literature, hardiness make people able to face stressful periods, keeps us off from the negative consequences of stress, anxiety. One of our research questions: is non- hardiness responsible for somatic symptoms development, and in what extent? It is not a secret anymore that stressful life easily results in anxiety, but there are also exceptional cases. The rule is not that simple. Additionally, the present research is an attempt to answer the question: to what extent stressful life experiences are determining anxiety and assist in producing somatic symptoms?

Taking into consideration that prolonged stress and anxiety, the lack of hardiness can manifest in somatic symptoms, the following hypothesis were formulated:

1. State and trait anxiety play an important role in producing somatic symptoms.

2. Non- hardy attitudes help the conception of anxiety and somatic symptoms.

3. Adolescents with high level of anxiety are less hardy, they present more somatic symptoms.

4. Stressful life events' experience explains nonhardiness, anxiety and somatic symptoms.

Hardy adolescents are less state-, and trait anxious, and they produce less somatic symptoms even if they experience the life events same stressful.

\section{Method}

\section{Participants}

Our sample contains 232 students from high school $(\mathrm{N}=128)$ and secondary school $(\mathrm{N}=94)$, children were volunteers attending. Before collecting data parents were asked to give written permission to their children to participate in the present study. Our sample consists of 92 boys and 140 girls, chosen from 7 different schools. Mean age of participants was 13.55 years $(\mathrm{SD}=2.07$, range 11 17). Mean age of boys 13.02 years $(\mathrm{SD}=2.09$, range 11 $16)$, the mean age of girls was $13.90(\mathrm{SD}=1.98$, range 11 17).

\section{Measures}

State and Trait Anxiety Inventory. We used Spielberger's (1973) State and Trait Anxiety Inventorydeveloped for children, translated to Hungarian by Sipos, for measuring anxiety. The entire inventory contains 40 items, the first 20 items measure the general (trait) anxiety, the additional 20 items detect the actual (state) anxiety. The items are rated on a 3 point Likert scale; state anxiety is considered high when scored points are above 38, while trait anxiety is considered high above 35 points.

Hardiness. According to Maddi's model (2006) we constructed a questionnaire for adolescents to measure hardiness as sum of the 3 components: control, challenge and commitment. The questionnaire also measures nonhardiness by scoring the statements which express the lack of control, lack of challenge and the lack of commitment. Hardiness and non-hardiness scales are considered as unitary scales, not being built of any subscales.

Subjects are asked to rate the statements on a 1-5 Likert scale: 1 slightly illustrates me, 5 totally illustrates 
me. Control component contains 9 items, each item has two statements, one shows the presence of control, the other statement shows the lack of having control above the events, circumstances, in this case we can compute the level of control and the level of lack of control: for example: 'a.) It is up to me what results I will achieve. b.) Results are not depending on me, very often luck plays important role in it.' The commitment component includes 8 items; each item has two statements, one refers to commitment while its statement pair expresses the lack of commitment. Example: 'a.) Usually I insist on my ideas even if the others are booing them. b.), I insist on my ideas until they are beneficial for me.' Challenge component contains 8 items. One of the statement-pairs shows the openness for challenges and the other shows the preference of accustomed solutions. Here is one example for it: 'a.) Tasks which make me think are interesting to me; I better prefer to work on them. b.) I prefer tasks which can be solved by routine'.

The hardiness score is computed from the sum of the 3 components: control, commitment and challenges. 25 items measure hardiness, the minimum point is 27 and the maximum is 125 points. Non-hardiness is computed from the sum of the lack of control, lack of commitment and lack of challenges. In total 25 items measures nonhardiness, the minimum score is 27 , maximum is 125 points. The internal validity was verified on Hungarian adolescents, Cronbach's Alpha of the hardiness scale was 0.71 (Kovács, 2015).

Life events. Based on Paykel Stressful Life Event Scale (1991) we shortened and adapted the scale to children, comparing to the original scale, which includes 61 events we used 30 stressful events. Additionally, we asked the subjects if something emotionally significant happened with them that was not listed in the Life Event Scale. The events were focusing on different areas: family (illness, divorcement of the parents, conflicts, moving to another town, losing a family member, marriage) existence (unemployment of the parents, debts, financial difficulties, poor living conditions), school (changing school, conflicts in the school, study's break off, bad marks), natural catastrophes (flood, fire, earthquake).Subjects were asked to mark the events that they experienced, and mark on a 15 Likert Scale how much they felt affected by a certain event.

Somatic Symptoms Checklist. We listed 18 somatic symptoms and we asked participants to rate on a 1-5 Likert scale how often they used to experience each somatic symptoms, 1- almost never, 5 several times on a week. Somatic symptoms included: migraine, nausea, diarrhea, gastrointestinal complaints, sweating, tachycardia, tachypnea, difficulty in breathing, dry mouth, sleeping problem etc.

\section{Procedure}

The data collection took place in the schools. Questionnaires were filled out on two consecutive days because in one time it would have been too long for the children. On day one they filled out the State and Trait Anxiety Inventory and the Somatic Symptoms Checklist, on the second day the Hardiness Scale and Life Events Scale were filled which were followed by chronicle disease related questions.

We classified subjects into low and high anxious category. In case of state anxiety those who reached a score lower than 38 were put in to the LSA (low state anxious) category. Adolescents who reached higher score than 38 were put in HAS (high state anxious) category. In case of trait anxiety who reached less than 35 points were put into LTA (low trait anxious) category and those who has higher score than 35 were ranked in HTA (high trait anxious).The hardy variable shows the difference between hardiness and non-hardiness, we subtracted the non-hardiness scores from the hardiness scores. Subjects above 26 points were considered as hardy persons.

\section{Statistical analyses}

Analyses were performed using SPSS version 17.0 for Windows. Pearson and Spearman correlations, linear-, and hierarchical regression models with enters method, distribution of residuals, independent sample $t$ test and Mann-Whitney $U$ test was conducted to test our hypothesis.

\section{Results}

Based on our data for each scales, we calculated Cronbach's Alpha to assess reliability: trait anxiety scale Cronbach's Alpha 0.89, state anxiety scale Cronbach's Alpha 0.86, hardiness scale Cronbach's Alpha 0.76, nonhardiness scale 0.75, life events Cronbach's Alpha 0.92 .

Descriptive statistics, Pearson and Spearman correlation between the variables are summarized in Table 1 and Table 2. No significant correlation was found between hardiness, state anxiety. Furthermore, there is a weak but significant negative correlation between hardiness and somatic symptoms $(\mathrm{r}=-.131, \mathrm{p}=.04)$. Our results show that there is a weaker but positive significant correlation between state anxiety and non-hardiness $(\mathrm{r}=.195, \mathrm{p}=.00)$, negative, significant correlation was found between hardiness and trait anxiety $(\mathrm{r}=-.274, \mathrm{p}=.00)$. Stronger correlations appear between trait anxiety and somatic symptoms $(r=.665$, $\mathrm{p}=.00)$, state and trait anxiety $(\mathrm{r}=.625, \mathrm{p}=.00)$, state anxiety and somatic symptoms $(\mathrm{r}=.513, \mathrm{p}=.00)$ and trait anxiety and non- hardiness $(\mathrm{r}=.413, \mathrm{p}=.00)$.

The life event variable was not normally distributed so Spearman correlation was computed. Results show that there is a stronger correlation between life events and state anxiety $(\rho=0.488, p=.00)$; life events and somatic symptoms $(\rho=0.368, p=.00)$. Stressful life events show a positive significant correlation with: hardiness $(\rho=.238$, $p=.00)$, non-hardiness $(\rho=.267, p=.00)$, trait anxiety $(\rho=$ $.299, \mathrm{p}=0.00$ ).

For testing the assumption- state and trait anxiety plays an important role in producing somatic symptomshierarchical regression was conducted. We used the enter method. Results are shown in Table 2. Model 1 shows trait anxiety as determinant in producing somatic symptoms. Model 2 shows the determinant power of state and trait anxiety. Trait anxiety plays an important role in producing somatic symptoms. According to our regression model, $26.3 \%$ of the somatic symptoms can be explained by it. Trait and state anxieties together have a bigger impact on somatic symptoms; they determine it in $46.1 \%$. The $\mathbf{R}^{2}$ change shows us that if we control trait anxiety, state anxiety would still explain $19.8 \%$ of somatic symptoms. Results of ANOVA assure that the regression model explanatory power is reliable, in case of trait anxiety the $\mathrm{F}=$ 82.115 and $\mathrm{p}=.000$; in case of trait +state anxiety $\mathrm{F}=97.932, \quad \mathrm{p}=.000$. Furthermore, we analyzed the distribution of residuals, the mean of the residuals is 0 and the standard deviation is 0.99 . 
The second hypothesis was tested with linear regression; we summarized the results in Table 3. Together with the linear regression analysis we conducted the One Sample Kolmogorov-Smirnov test, in all three cases means are 0 and the standard deviation is $0.99, \mathrm{p}>0.05$, so the residuals are normally distributed. Non-hardy attitudes are only $3 \%$ responsible for trait anxiety, $9 \%$ for somatic symptoms and $17 \%$ for state anxiety.

Table 1. Descriptive statistics and correlations between the included variables

\begin{tabular}{|c|c|c|c|c|c|c|c|c|c|}
\hline Measure & & & Mean & SD & 1 & 2 & 3 & 4 & 5 \\
\hline 1. & Hardiness & & 15.98 & 16.42 & & & & & \\
\hline 2. & Non-hardiness & & 73.20 & 13.17 & $-.602 * *$ & & & & \\
\hline 3. & State Anxiety & & 32.53 & 6.06 & -.107 & $.195 * *$ & & & \\
\hline 4. & Trait Anxiety & & 34.97 & 8.35 & $-.274 * *$ & $.413 * *$ & $625 * *$ & & \\
\hline 5. & $\begin{array}{l}\text { Somatic } \\
\text { Symptoms }\end{array}$ & & 36.30 & 11.44 & $-.131 *$ & $.314 * *$ & $.513 * *$ & $.665^{* *}$ & \\
\hline 6. & $\begin{array}{l}\text { Stressful } \\
\text { events }\end{array}$ & life & 22.30 & 24.71 & $0.238^{* *}$ & $0.267 * *$ & $0.299 * *$ & $0.488^{* *}$ & $0.368 * *$ \\
\hline
\end{tabular}

Table 2. Summary of Hierarchical Regression Analysis for Variables Predicting Somatic Symptoms

\begin{tabular}{|c|c|c|c|c|c|c|}
\hline & Model 1 & & & Model 2 & & \\
\hline Variable & B & SE B & B & B & SE B & $\beta$ \\
\hline Somatic symptoms & 5.153 & 3.489 & & -.952 & 3.071 & \\
\hline 1. Trait anxiety & .0960 & .106 & .513 & & & \\
\hline 2. Trait anxiety & & & & .318 & .115 & .170 \\
\hline state anxiety & & & & .770 & .084 & .562 \\
\hline $\mathrm{R}$ & .513 & & & .679 & & \\
\hline $\mathrm{R}^{2}$ & .263 & & & .461 & & \\
\hline$F$ for change $R^{2}$ & $82.115^{* *}$ & & & $84.086^{* *}$ & & \\
\hline
\end{tabular}

Table 3. Summary of Linear Regression Analysis of Somatic Symptoms, Anxiety and Non-hardiness

\begin{tabular}{lllll}
\hline Variables & Beta & T & Sig. & $\mathbf{R}^{2}$ \\
\hline $\begin{array}{l}\text { Constant (Non-hardy) } \\
\text { State Anxiety }\end{array}$ & 0.19 & 3.04 & 0.00 & 0.17 \\
$\begin{array}{l}\text { Non-hardy- } \\
\text { Trait Anxiety- }\end{array}$ & 0.41 & 6.88 & 0.00 & 0.03 \\
$\begin{array}{l}\text { Non-hardy- } \\
\text { Somatic }\end{array}$ & 0.31 & 5.01 & 0.00 & 0.09 \\
\hline
\end{tabular}

Table 4. The comparison of somatic symptoms and hardiness level at adolescents with high and low level of anxiety

\begin{tabular}{lllllll}
\hline \multirow{2}{*}{ Somatic } & Group & N & Mean & t & df & p \\
& LSA & 148 & 31.70 & -9.58 & 230 & 0.00 \\
\multirow{3}{*}{ Hardy } & HAS & 84 & 44.40 & & & 0.00 \\
& Somatic & 148 & 19.41 & 4.38 & 230 & 0.00 \\
\multirow{2}{*}{ Hardy } & HAS & 84 & 9.94 & & 230 & 0.02 \\
& LTA & 164 & 33.29 & -6.78 & & 230 \\
\end{tabular}

Notes: LSA- low state anxious, HAS-high state anxious, LTA-low trait anxious, HTA-high trait anxious. 
Table 5. The comparison of stressful life events at adolescents high and low level of anxiety

\begin{tabular}{|c|c|c|c|c|c|c|}
\hline & Group & $\mathbf{N}$ & Mean Rank & $\overline{\mathbf{U}}$ & $\mathbf{Z}$ & $\mathbf{p}$ \\
\hline \multicolumn{7}{|l|}{ Stressful life events } \\
\hline & LSA & 148 & 97.77 & 3443.50 & -5.64 & 0.00 \\
\hline & HSA & 84 & 149.51 & & & \\
\hline & LTA & 164 & 106.22 & 3890.00 & -3.62 & 0.00 \\
\hline & HTA & 68 & 141.29 & & & \\
\hline
\end{tabular}

Notes: LSA- low state anxious, HAS-high state anxious, LTA-low trait anxious, HTA-high trait anxious.

\begin{tabular}{lllll} 
Table 6. The linear regression model of stressful life events, anxiety and non-hardiness \\
\hline & Beta & t & Sig. & $\mathbf{R}^{\mathbf{2}}$ \\
\hline 1. Life events- State Anxiety & 0.130 & 59.20 & 0.00 & 0.129 \\
2. Life events- Trait Anxiety & 0.365 & 46.28 & 0.00 & 0.034 \\
3. Life events-Non-hardiness & 0.280 & 61.74 & 0.00 & 0.082 \\
\hline
\end{tabular}

Table 7. Comparison of anxiety and somatic symptoms at hardy and non-hardy person

\begin{tabular}{lllllll}
\hline & Group & $\mathbf{N}$ & Mean & t & df & p \\
\hline Somatic & Hardy & 65 & 32.90 & -3.04 & 230 & 0.00 \\
& Non-hardy & 167 & 37.92 & & & 0.52 \\
State Anxiety & Hardy & 65 & 32.12 & -0.63 & 230 & \\
& Non-hardy & 167 & 32.68 & & & 0.00 \\
& Hardy & 65 & 33.29 & -2.84 & 230 & \\
& Non-hardy & 167 & 43.54 & & & \\
\hline
\end{tabular}

According to the literature our assumption was that adolescents with high state and trait anxiety produces more somatic symptoms; they are less hardy and they experienced more stressful life experiences. Those who were achieving more than 38 points on the state anxiety scale were considered state anxious, those who were underneath 38 points were not considered state anxious, similar with trait anxiety, whose score was more than 35 points were considered generally anxious, adolescent underneath 35 point were not considered generally anxious. In our sample 84 adolescents presents high state anxiety, 148 adolescents experiencing low state anxiety. In case of trait anxiety 64 adolescents are considered generally anxious. Somatic symptoms and hardiness present normal distribution. To compare the groups we conducted an Independent Sample T test.

Results in Table 4 show that adolescents with high level of state and trait anxiety produce significantly more somatic symptoms and they are significantly less hardy than adolescents with low level of anxiety.

Stressful life events are not normally distributed, so we compared with Mann-Whitney U test. Based on the results displayed in Table 5, we can say, that adolescents with high level of anxiety experienced more stress, more emotional load during life events, than adolescents with lower level of anxiety.

We used linear regression, enter method and we also conducted the One Sample Kolmogorov-Smirnov test to verify if stressful life events can explain anxiety and nonhardy attitude. In all three cases means are 0 and the standard deviation is $0.99, \mathrm{p}>0.05$, so the residuals are normally distributed.

Results in Table 6 show that stressful life events give a weak explanation for developing trait anxiety $(3,4 \%)$ or non-hardy attitudes $(8,2 \%)$. It seems to have stronger explanation effect on state anxiety, $12,9 \%$. Stressful life events are not the main agent in causing anxiety or nonhardy attitudes.
Based on theories and previous researches, we supposed that hardy adolescents are less state and trait anxious and they have less somatic symptoms even if they experience life events the same stressful like non-hardy counterparts. We used Mann-Whitney U test to compare how stressful hardy and non-hardy adolescents experience their life events $(\mathrm{u}=5226$, mean rank 113.41, $\mathrm{Z}=-0.43$, sig. $0.66)$.

We found no significant differences. As Table 7 shows, we can state that hardy adolescents experience less somatic symptoms and they are lower in trait anxiety. There is no significant difference in state anxiety level between the two groups.

\section{Discussion}

Anxiety is known as the most common psychological disorder at children and adolescents (Beesdo- Baum, Knappe, 2012). In our study the prevalence of it is relatively high. In our sample $36.20 \%$ of the participants belonged to the highly state anxious category and $27.58 \%$ of them is considered highly trait anxious. Like others (Fielding et al, 2016, Gold, 2011, Sadaghiani, 2011) we also came to the conclusion that anxiety, mainly trait anxiety plays an important role in producing somatic symptoms. Individuals who have a predisposition to magnify adversity (Spielberger, 1972) perceive and interpret more situations harmful and they activate their state anxiety too. For this tension their bodies frequently react by producing somatic symptoms.

Hardiness is well known for its stress buffering (Kobasa, 1979, Maddi, 2013) effect. We tried to find answers if the lack of hardiness, non-hardy attitudes contribute to anxiety and somatic symptoms. Based on our results we can say that non-hardy attitudes give a weak explanation for trait anxiety or somatic symptoms. Nonhardy attitudes have a stronger explanatory effect on state anxiety. Non-hardy people have difficulties to buffer stress, they probably become easier stressed, and they feel more 
often lost, helpless and inhibited that lead to anxiety. In literature we find less information about how non-hardy attitudes are formed. It would be easier to understand its relationship with trait anxiety if we now the development of it. It is hard to predict how much time is needed in prolonged stress conditions, how weak the coping mechanism should be, or how helpless should one feel, how many environmental risks should one experience to become non-hardy.

We assumed that stressful life events, and the way how adolescents experience them, could determine nonhardiness, anxiety and somatic symptoms. Our results present that stressful life events give a trivial explanation for trait anxiety. It seems that trait anxiety is not formed by traumatic events. Non-hardy attitudes could also poorly be explained by stressful life events, this show us that only negative experiences are not enough to result non-hardy attitudes. There is still not a consensus about what is hardiness or resilience, as it appears to us it is more than resistance to stress. Maddi (2007) considers it as a multitude of attitudes and strategies. According to our findings we can state that stressful life events can explain the prevalence of state anxiety, but only in $13 \%$ and it is able to give less explanation for trait anxiety and nonhardiness. In other words, we came to the conclusion that life events do not determine causes of anxiety and nonhardiness.

Our findings show that adolescents with high state and trait anxiety produce more somatic symptoms and they are less hardy than adolescents who have low level of state-, and trait anxiety.

Our conclusion is similar to Beasley Thompson and Davidson (2003) findings: hardy people have less somatic symptoms and they are less trait anxious (Hanton, Evasn, Neil, 2003).Hardy and non-hardy adolescents show similar emotional charge caused by different life events and they experience state anxiety on a similar level, but they might differ in their reactions, actions, behaviors during adverse conditions.

\section{Limitations of the study}

In the present study we used self- reported anxiety; somatic symptoms, hardiness measures. Some objective data like biological measures (blood pressure, heart rate, breathing frequency, brain activity etc.) could give a more precise picture from the relationship of anxiety and somatic symptoms. Human reactions for adverse situations show far away more distinguished pattern than "fight or flight". In addition, adaptive behaviors can vary a lot. Hardiness should be measured in different experimental situation accompanied by a semi-structured interview, to get a more adequate picture about hardy and non- hardy adolescent behavior and way of thinking. It might be useful to detect the signs of control, commitment and challenge and define the optimal level or the limits of the concept.events.

\section{References}

Abdolhosseini, A., Hasel, K. H., Zalani, L. K. (2012). The moderating role hardiness and perfectionism variables and the relationship between stress and physiologic responses. Procedia- Social and Behavioral Sciences, 46, 5868 5874.

Bartone, P. T., Ursano, R. J., Wright, K. M. \& Ingraham, L.H. (1989). The impact of a military air disaster on the health of assistance workers. Journal of Nervous and Mental Disease, 177, 317-328.

Beasley, M., Thompson, T., Davidson, J. (2003). Resilience in response to life stress: the effects of coping style and cognitive hardiness. Journal of Personality and Individual Differences, 34, 77-95.

Beesdo-Baum, K., Knappe, S. (2012). Developmental epidemiology of anxiety disorder. Child and Adolescent Psychiatric Clinics of North America, 21, 457-478.

Beesdo, K., Jacobi, F., Hoyer, J., Low, N. C., Hofler, M., Wittchen, H.U. (2010). Pain associated with specific anxiety and depressive disorders in a nationally representative population sample. Social Psychiatry and Psychiatric Epidemiology, 45, 89-104. In: Bekhuis, E., Boschloo, L., Rosmalen, J. G. M., Shoevers, R. A. (2015). Differential associations of specific depressive and anxiety disorders with somatic symptoms. Journal of Psychosomatic Research, 78, 116-122.

Bekhuis, E., Boschloo, L., Rosmalen, J. G. M., Shoevers, R. A. (2015). Differential associations of specific depressive and anxiety disorders with somatic symptoms. Journal of Psychosomatic Research, 78, 116-122.

Besharat, M. A., Hasel, K. M. (2011). Relationship of perfectionism and hardiness to stress- induced psychological responses. Procedia- Social and Behavioral Sciences, 30, 113-118.

Cattel, R. B., Scheier, I. H. (1961). The meaning and measurement of neuroticism and anxiety, Ronald Press, New York In: Spielberger, C. D. (1972). Anxiety Current Trends in Theory and Research, Vol. II., Academic Press, New York.

Connor, K. M., Davidson, J. R. T. (2003). Development of a new resilience scale: the Connor-Davidson Resilience Scale (CD-RISC). Depression and Anxiety, 18, 76-82.

Cruz, C., Duarte, J., Nelas, P., Antunes, A., Almedia, M. (2014). Anxiety and depression in adolescents with hostile behavior. Atencion Primaria, 46, 107-111.

Dávid I., Fülöp M., Pataky N., Rudas J. (2014). Stressz, megküzdés, versengés, konfliktusok. Magyar Tehetséggondozók Szervezetének Szövetsége, 11-23.

Haddadi, P., Besharat, M., A. (2010). Resilience, vulnerability and menthalhelath. Procedia-Social and Behavioral Sciences, 5, 639-642.

Hanton, S., Evans, L., Neil, R. (2003). Hardiness and the competitive trait anxiety response. Anxiety, Stress and Coping: An International Journal, 16, 167-184

Hamblin, R. J., Lewin, A. B., Salloum, A., Crawford, E. A., McBrige, N. M., Storch, E. A. (2015). Clinical characteristics and predictors of hoarding in children with anxiety disorder. Journal of Anxiety Disorder, 36, 9-14.

Kobasa, S. C. (1979). Stressful life events, personality, and health: An inquiry into hardiness. Journal of Personality and Social Psychology, 37, 1-11.

Koeppen, B. M. and Stanton, B. A. (2009). Berne Levy Physiology. 6th ed. Barcelona: Elsevier-Mosby. In: Ortega, M., Saavedra, S. (2014). Resilience physiological assembley and psychosocial factors. Procedia- Social and Behavioral Sciences, 132, 447-453.

Kovács I. K. (2015). A keményenhelytálló attitűd és iskolai eredményesség közötti kapcsolat XI. osztályos diákok körében. In: Barabási Tünde, Péter Lilla (Szerk.) Kompetencia- és tudástranszfer az oktatásban, VI.Tudományos ülésszak előadásai. Kolozsvári Egyetemi Kiadó, 79-88.

Maddi, S. R. (2002). The story of hardiness: Twenty years of theorizing, research, and practice. Consulting Psychology Journal: Practice and Research, 54, 175-185.

Maddi, S. R. (2005). On hardiness and other pathways to resilience. American Psychologist, 60, 261-264. 
Maddi, S. R. (2007). Relevance of hardiness assessment and training to the military context. Military Psychology,19, 61-70.

Maddi, S. R. (2013). Personal Hardiness as the Basis for Resilience. Turning Stressful Circumstances Into Resilient Growth. Retrieved January 27, 2016, from http://www.springer.com/978-94-007-5221-4

Ortega, M., Saavedra, S. (2014). Resilience physiological assembly and psychosocial factors. Procedia-Social and Behavioral Sciences, 132, 447-453.

Patrick, C. J. \& Bernat, E. M. (2009). Neurobiology of psychopaths. In G. G. Berntson\& J. T. Cacioppo (Eds.): Handbook of neuroscience for the behavioral sciences Vol. 2, pp. 1110-1131). Hoboken, NJ, John Wiley \& Sons.

Paykel, E. S. (1991). Stress and life events. In: Davidson, L., Linoilla, M., (eds.): Risk factors for youth suicide, New York, Hemisphere. In: Perczel Forintos D., Kiss Zs., Ajtay Gy. (2005). Kérdöivek, becslöskálák a klinikai pszichológiában. Országos Pszichátriai és Neurológiai Intézet.

Sandvik, A., M., Hansen, A. L., Hystad, S. W., Johnsen, B. H., Bartone, P. T. (2015). Psychological hardiness as a mediator of the psychopathy-anxiety relationship in a prison setting. Personality and Individual Differences 72, 30-34

Shagadiani, N. S. K. (2011). The role of hardiness in decreasing stressors and biological, cognitive and mental reactions. Procedia- Social and Behavioral Sciences 30 , 2427-2430

Silverthorn, D. U. (2008). Human Physiology. An Integrated approach. 4th ed. Madrid: Panamericana. In: Ortega, M., Saavedra, S. (2014). Resilience physiological assembly and psychosocial factors. Procedia-Social and Behavioral Sciences 132, 447-453.

Spielberger, C. D. (1972). Anxiety Current Trends in Theory and Research, Vol. II., Academic Press, New York

Spielberger, C. D., Edwards, C.D., Mountori, J., Lusheme, R. (1973). State-Traint Anxiety Inventory for Children. Palo Alto, CA, Consulting Psychiologist Press. In: Perczel Forintos D., Kiss Zs., Ajtay Gy. (2005). Kérdöivek, becslöskálák a klinikai pszichológiában. Országos Pszichátriai és Neurológiai Intézet.

Wiebe, D. J. (1991). Hardiness and stress moderation - A test of proposed mechanisms. Journal of Personality and Social Psychology, 60, 89-99.

Wolin, S. ,Wolin, S. (1993). The resilient self: how survivors of troubled families rise above adversity. Nueva York, E.E.U.U: Villard Books. In: Ortega, M., Saavedra, S. (2014). Resilience physiological assembly and psychosocial factors. Procedia- Social and Behavioral Sciences, 132, 447-453. 